\title{
Correction to: Does Surgery Without Lugol's Solution Pretreatment for Graves' Disease Increase Surgical Morbidity?
}

Frederic Mercier $^{1} \cdot$ Mathieu Bonal $^{1} \cdot$ Florian Fanget $^{1} \cdot$ Laure Maillard $^{1}$ Nathalie Laplace $^{1} \cdot$ Jean-Louis Peix ${ }^{1} \cdot$ Jean-Christophe Lifante $^{1,2}$

Published online: 8 February 2018

(C) Société Internationale de Chirurgie 2018

\section{Correction to: World J Surg https://doi.org/10.1007/s00268-017-4443-3}

In the original article, Mathieu Bonal's last name was spelled incorrectly. It is correct as reflected here. The original article has also been updated.

The original article can be found online at https://doi.org/10.1007/ s00268-017-4443-3.

$\triangle$ Jean-Christophe Lifante

jean-christophe.lifante@chu-lyon.fr

1 The Department of Digestive and Endocrine Surgery, CHU Lyon Sud, Hospices Civils de Lyon, University of Lyon, 165 Chemin du Grand Revoyet, 69495 Pierre Bénite, France

2 EA 7425 HESPER, Health Services and Performance Research, Université Claude Bernard Lyon 1, Domaine Rockefeller- 4eme étage (aile CD), 8 Avenue Rockefeller, 69373 Lyon 8, France 